\title{
Management of bovine tuberculosis in Michigan wildlife: Current status and near term prospects
}

\author{
Daniel J. O'Brien ${ }^{\mathrm{a}, *}$, Stephen M. Schmitt ${ }^{\mathrm{a}}$, Scott D. Fitzgerald ${ }^{\mathrm{b}, \mathrm{c}}$, Dale E. Berry ${ }^{\mathrm{d}}$ \\ ${ }^{a}$ Wildlife Disease Laboratory, Michigan Department of Natural Resources, 4125 Beaumont Road, Room 250, Lansing, MI 48910-8106, USA \\ ${ }^{\mathrm{b}}$ Diagnostic Center for Population and Animal Health, College of Veterinary Medicine, Michigan State University, East Lansing, MI 48824, USA \\ ${ }^{\mathrm{c}}$ Department of Pathobiology and Diagnostic Investigation, College of Veterinary Medicine, Michigan State University, East Lansing, MI 48824, USA \\ ${ }^{\mathrm{d}}$ Mycobacteriology Laboratory, Michigan Department of Community Health, 3350 N. Martin Luther King Jr. Blvd., Lansing, MI 48909, USA
}

\section{A R T I C LE I NFO}

\section{Keywords:}

Bovine tuberculosis

Mycobacterium bovis

Wildlife

White-tailed deer

Odocoileus virginianus

\begin{abstract}
A B S T R A C T
Surveillance and control activities for bovine tuberculosis (bTB) in free-ranging Michigan white-tailed deer (Odocoileus virginianus) have now been underway for over a decade. Significant progress has been made, lowering apparent prevalence in deer in the core area by $>60 \%$, primarily via reduction of deer densities through hunting, and restrictions on public feeding and baiting of deer. These broad strategies of the Michigan Department of Natural Resources (MDNR), implemented with the cooperation of Michigan deer hunters, halved the deer population in the bTB endemic area. However, as hunters see fewer deer, their willingness to sustain aggressive harvests has waned, and public resentment of control measures has grown.

During the past four years, apparent prevalence in core area deer has held approximately steady just below $2 \%$. After bottoming out in 2004 at an estimated $10-$ $12 \mathrm{deer} / \mathrm{km}^{2}$, deer numbers have since rebounded by $\sim 30 \%$. Public compliance with baiting and feeding restrictions has been variable. In general, hunters in the core area do not perceive bTB as a problem, in spite of 13 years of MDNR outreach. To date, MDNR has expended more than US $\$ 23$ million on TB-related activities. Of late, a substantial portion of that funding has been diverted to support other programs which have suffered from budget shortfalls.

Livestock herd breakdowns continue to occur sporadically, averaging 3-4 per year 2005 to present. In total, 46 cattle and 4 captive deer herds have been diagnosed bTB positive statewide, the majority yielding only 1 positive animal. Five cattle herds were twice infected, one thrice. Michigan Department of Agriculture (MDA) policy emphasis has shifted towards obtaining producer support for wildlife risk mitigation and farm biosecurity. Funding has proven a limiting factor, with the majority of the US\$63 million spent to date devoted to whole herd testing.

Nevertheless, some initiatives justify cautious optimism. Promising research to support eventual vaccination of wild deer continues. Some hunters and landowners have begun to recognize the costs of high deer densities and supplemental feeding. A peninsula-wide ban on baiting and feeding was enacted. Some cattle producers, recognizing their precarious circumstances, have begun work to change long-held prevailing opinions among their peers about farm biosecurity. Yet formidable challenges remain, and evidence suggests that eradication of bTB, if it can be achieved, will take decades, and will require greater public and political resolve than has been demonstrated thus far.
\end{abstract}

(C) 2011 Published by Elsevier B.V.

\footnotetext{
* Corresponding author. Tel.: +1 517336 5030; fax: +1 5173374920.

E-mail address: obriend@michigan.gov (D.J. O’Brien).
} 


\section{Introduction}

Surveillance and control activities for bovine tuberculosis (bTB), caused by Mycobacterium bovis, in free-ranging Michigan white-tailed deer (WTD; Odocoileus virginianus) have now been underway for over a decade (Schmitt et al., 1997; O'Brien et al., 2006). Numerous experimental (Butler et al., 2001; Clarke et al., 2007; Diegel et al., 2002; Fitzgerald et al., 2003a,b, 2005; Palmer et al., 2002b) and field (DeLiberto, 2004; O'Brien et al., 2008; VerCauteren et al., 2008a; Wilkins et al., 2008) investigations carried out both within the Michigan Department of Natural Resources (MDNR) and a by a variety of other investigators have thus far confirmed the WTD as the sole maintenance host in the Michigan outbreak. Pathological (Palmer et al., 1999, 2002a; O'Brien et al., 2001) and basic epidemiological (Hickling, 2002; O'Brien et al., 2002, 2004, 2006) characteristics of bTB in WTD, as well as mechanisms of intra- and interspecies transmission (Palmer et al., 2001, 2004a,b; Palmer and Whipple, 2006) are now all well characterized. Significant progress has been made, lowering apparent prevalence in deer in Deer Management Unit (DMU) 452 (the core outbreak area) by $>60 \%$, primarily via reduction of deer densities through hunting, and restrictions on public feeding and baiting of deer. These broad strategies of the MDNR, implemented with the cooperation of Michigan deer hunters, halved the deer population in the bTB endemic area by 2004 . However, as hunters see fewer deer, their willingness to sustain aggressive harvests has waned and public resentment of control measures has grown (O'Brien et al., 2006).

In 2008, 733,998 licensed deer hunters harvested approximately 489,922 WTD statewide (Frawley, 2009). These hunters purchased more than 1.5 million deer harvest tags. The economic value of deer hunting to Michigan's economy is substantial. For example, in 2006, hunters spent US\$507 million hunting WTD in Michigan (U.S. Department of Interior, 2008). Such impacts confer considerable intrastate political clout to hunters, thus far equal to, or arguably exceeding, that commanded by the state's livestock producers. Thus despite the predominance of livestock interests at the national level, maintaining hunter cooperation is critical not only to bTB control in WTD, but the overall control of bTB in cattle. Because the Michigan outbreak remains a significant barrier to the nationwide eradication of bTB in livestock (Gilsdorf et al., 2006), much depends on keeping Michigan deer hunters engaged and actively working towards bTB eradication.

\section{Current status of $M$. bovis in free-ranging wildlife}

\subsection{Surveillance}

To date, 178,199 WTD have been tested for bTB statewide, with 633 having been confirmed positive by mycobacterial culture. Six hundred thirteen (97\%) of these deer originated from the five county bTB endemic area of Alcona, Alpena, Montmorency, Oscoda and Presque Isle counties. Since 2003, apparent prevalence (Rogan and Gladen, 1978; Martin et al., 1987) in DMU 452 has shown only minor fluctuations around a level just below $2 \%$
(Fig. 1a). During the same period, apparent prevalence in the remainder of the five county endemic areas outside the core has remained an order of magnitude lower at approximately $0.2 \%$. Previous work has shown that apparent prevalence of bTB in WTD underestimates true prevalence by $\sim 25 \%$ (O'Brien et al., 2004). While statistically significant decreasing trends in prevalence (CochranArmitage test for trend, two-tailed) have been documented in DMU 452 for both yearlings ( $p<0.002$; Fig. $1 \mathrm{~b}$ ) and deer of all ages $(p<0.0001)$ since surveillance began in 1995 , there has been no significant trend for either age group ( $p=0.42$ and $p=0.25$, respectively) since 2002. This recent lack of a consistent downward direction for apparent prevalence has been the subject of considerable concern on the part of MDNR in recent years. After bottoming out in 2004 at an estimated 80,000 in the five county endemic areas, deer numbers as determined by sex-age kill (SAK) modeling (Mattson and Moritz, 2008) have since rebounded to an estimated 110,000 in 2008 (Fig. 1c). In general, trends in apparent prevalence have tracked population estimates well over time. While other factors could account for the lack of a consistent downward direction for bTB prevalence, the increase in the WTD population in the 5 county endemic areas since 2004 is perhaps the most plausible explanation.

There is a strong correlation ( $r=0.77$; Fig. 2$)$ between apparent bTB prevalence in yearling (1-1.5 year old) deer and the size of the deer population in the five county endemic areas, supporting previous evidence of densitydependent transmission (Hickling, 2002). The prevalence of bTB in yearling deer has long been used in Michigan as a crude index of the rate of new infections, because positive deer could only have acquired bTB within the previous year (O'Brien et al., 2006). Although interpretation of this relationship requires caution, these data suggest that a SAK estimate of about 80,000 deer across the $8047 \mathrm{~km}^{2}$ endemic area (corresponding to a density of $\sim 10$ deer/ $\mathrm{km}^{2}$ ) could be associated with a very low incidence of new infections in young deer. Notably, this figure is quite close to the threshold density of 12 deer $/ \mathrm{km}^{2}$ estimated in a separate analysis (Hickling, 2002). Of course, deer are not distributed uniformly on the landscape, and spatially explicit simulations will be necessary to estimate this density/incidence relationship with greater confidence.

Outlying bTB cases have occurred rarely in areas relatively distant from the five county endemic areas (Blanchong et al., 2002; O’Brien et al., 2002). In January 2008, hunters in Shiawassee County, approximately $185 \mathrm{~km}$ south of the bTB endemic area, presented the carcass of a 1.5 year old doe with pleural lesions typical of disseminated bTB (O'Brien et al., 2001), to MDNR. Lung, pleura and medial retropharyngeal lymph node samples cultured positive for $M$. bovis, with the strain isolated identical (by spoligotyping, restriction fragment length polymorphisms IS6110 and TBN12, and mycobacterial interspersed repetitive units) to that of other infected freeranging deer identified to date. Analysis of microsatellite loci (Blanchong et al., 2002), though statistically inconclusive, suggested that the multilocus genotype of the bTB positive deer was at least 2.5 times more likely to have originated from the five county endemic areas than from 

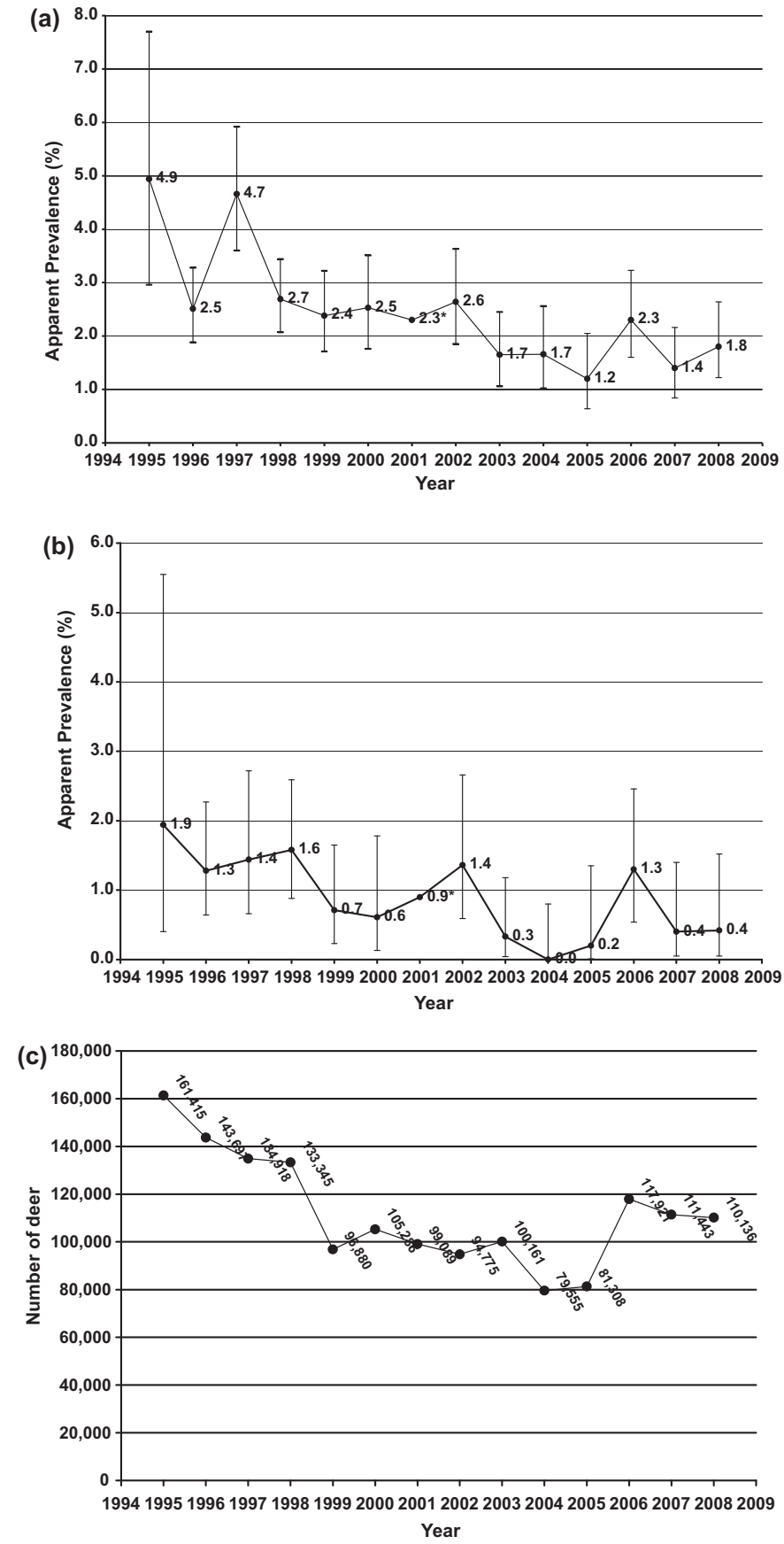

Fig. 1. Trends in apparent prevalence of bovine tuberculosis (bTB) in all age (a) and yearling (b) free-ranging white-tailed deer in Deer Management Unit 452; and (c) sex-age kill (SAK) estimated deer population in the five county bTB endemic area, Michigan, USA, 1995-2008.

Shiawassee County (Scribner, 2008). Radiotelemetry studies in the endemic area have documented maximum movement distances for does of $40 \mathrm{~km}$ (Sitar, 1996) and $26 \mathrm{~km}$ (Garner, 2001), suggesting it is extremely unlikely that the infected doe moved to Shiawassee County without human assistance. Rather, it is more plausible that the deer was moved by humans or escaped from a captive cervid facility in the area. That $M$. bovis is being maintained in deer across broad areas of Michigan's Lower Peninsula as far south as Shiawassee County seems unlikely, as that would imply that densities everywhere are just high enough to sustain bTB transmission, but not to allow it to increase to more observable levels. It is possible however that some mobile, long-lived infected deer gradually move out from DMU 452 into fringe areas, infecting a few additional local deer along the way. Such a scenario might support low prevalence of infected deer over a relatively broad area, even though bTB is not truly sustainable there. 


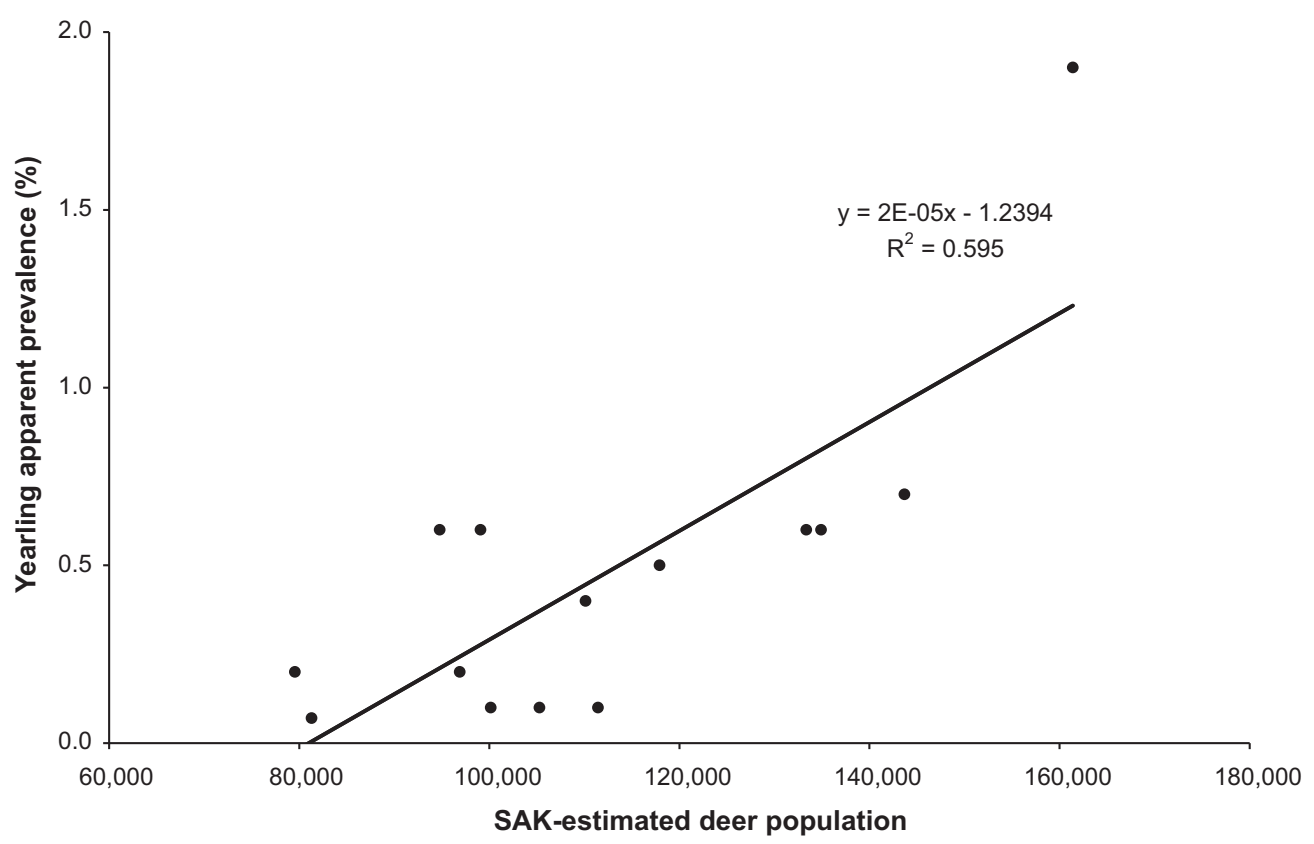

Fig. 2. Correlation plot of apparent prevalence of bovine tuberculosis (bTB) in yearling white-tailed deer versus the sex-age kill (SAK) estimated white-tailed deer population, Alcona, Alpena, Montmorency, Oscoda and Presque Isle Counties, Michigan, USA 1995-2008.

The fact that so few such animals have been detected to date by statewide active surveillance of WTD may simply be a function of the low probability of detection given logistically feasible sample sizes when the disease is present only at a very low prevalence.

The geographic distribution of bTB cases in WTD has remained largely stable over time (Hickling, 2002; Hickling et al., 2003; O'Brien et al., 2006). However, in the past two years, three bTB-positive deer have been harvested in Iosco County, immediately southeast of the endemic area. Prior to 2007, only one of 3997 deer tested from that county were bTB-positive. Rivers influence disease spread (Blanchong et al., 2008), and a relatively large river (the Au Sable) could be acting as a movement corridor for WTD dispersal from the endemic area. The recent Iosco County cases may be evidence of increasing population prevalence spreading southward. Consequently, MDNR has extended liberalized hunting regulations in force for a decade in the five county endemic areas to Iosco County as well. These regulations enable more aggressive harvest of antlerless deer (via effectively unlimited availability of hunting licenses, discounted license fees, and extended hunting seasons), and enhanced enforcement of baiting and feeding bans.

The free-ranging Michigan elk (Cervus elaphus nelsoni) population is subject to mandatory bTB testing of all hunter harvested animals, as well as testing of recovered carcasses of non-harvest mortalities (O'Brien et al., 2006, 2008; Schmitt et al., 2002). Elk are the only Michigan species other than WTD which existing evidence suggests could play an epidemiologically significant role in the current outbreak. To date, five of 2164 elk tested since 1996 have cultured positive for $M$. bovis, the most recent in 2006. None displayed tuberculous lesions outside the head. Two of five had no gross lesions whatsoever, and two of the remaining three bore only minimal gross lesions, suggesting they were unlikely to be shedding large numbers of mycobacteria. Together with the relatively high fraction of the elk population tested annually (10$12 \%$ ) and the low estimated true prevalence of infection (0.6\%; O'Brien et al., 2008), surveillance to date suggests elk remain only spillover hosts of bTB.

\subsection{Management}

Beginning January 2008, MDNR increased the availability of Disease Control Permits (DCPs), expanding a bTB control strategy initiated in 1998. The expansion was intended in part to address cattle producers' perceptions that DCPs were either unavailable to them or prohibitively difficult to obtain. The strategy was also intended to provide producers with another tool to manage freeranging deer on their lands and harass deer away from areas where feeds are stored and cattle are fed. Essentially, DCPs are permits to legally shoot WTD outside of established autumn hunting seasons; they can be used year round. Permits are mass-mailed free of charge to all cattle producers in the five county endemic areas. They are also available on request to all others in DMU 452 who own more than 14 hectares; these are mailed a letter of invitation annually to participate in the program. Since January 2008, 1175 DCPs with 6427 kill tags have been mailed to cattle producers. From those opportunities to kill deer, 776 deer have been shot ( $12 \%$ of available kill tags) by 195 cattle producers. Those farmers comprise $29 \%$ of the eligible cattle producers to whom permits were mailed. Two deer shot on cattle farms $(0.3 \%)$ have cultured bTB positive thus far. Public response to the program has been mixed. Despite their relatively low rate of participation, cattle producers and their advocacy groups have generally welcomed expansion of the DCP program. However, 
backlash from the mass media and the public has also been in evidence. While the availability of DCPs to non-farm landowners has blunted arguments of special treatment to some extent, the fact that deer can be shot regardless of sex or age, year-round (including when they have suckling fawns), and by methods such as night spotlighting (which are illegal during hunting seasons) has at times led to vocal accusations of mismanagement of the public resource on the part of MDNR. Some cattle producers using DCPs have also reported threats of violence by adjacent landowners and deer hunters directed towards them and their livestock.

The use of foodstuffs as an aid in the harvest of deer (baiting) and the artificial feeding of deer either for recreation or to supplement their natural diets (feeding) has technically been illegal since 2002 in the seven counties from which $98 \%$ of all bTB-positive deer have originated (the five county endemic areas plus two counties immediately adjacent to the west, Crawford and Otsego). Public compliance with baiting and feeding restrictions has been variable. Application of the feeding and baiting ban to only seven counties was a policy decision made to minimize public opposition in areas where the prevalence of bTB was low, as well as to stabilize regulations to facilitate better enforcement and prosecution (O'Brien et al., 2006; Rudolph et al., 2006). However, residents of the seven affected counties came to resent their area being singled out for special treatment, given the fact that bTB has for a decade been known to be widely distributed, albeit at low prevalence, across wide areas of northern Michigan. By 2007, the ban was being widely ignored. With a limited number of conservation officers available to issue citations (one conservation officer per approximately 4800 deer hunters), people using bait illegally simply took their chances that they would not be caught, or merely considered the fines received (US\$500 or less) as a "cost of doing business". The sales of foodstuffs for use as deer bait and feed continue to remain legal statewide. Michigan law does not consider agricultural commodities for sale to be bait or feed until they are used by an individual for that purpose. Thus, banning sales has been considered unworkable from a legal perspective.

In general, hunters in the core area, and indeed across Michigan, do not perceive bTB to be a problem, in spite of 13 years of MDNR outreach. An opinion survey of 5598 deer hunters statewide (a 64\% response rate from the 8815 people receiving the questionnaire) carried out by MDNR Wildlife Division in 2006 provides telling insight (Frawley and Rudolph, 2008). When asked which issues should be considered by MDNR when setting hunting regulations statewide, $77 \%$ characterized problems with deer herd health to be important or very important. Only hunter dissatisfaction with the number of bucks (82\%) and the overall number of deer (81\%) were considered more important. However, when asked how extensive these problems were currently, only $16 \%$ of respondents considered problems with deer herd health to be very extensive or moderate, compared to $72 \%, 67 \%$ and $62 \%$ of respondents who considered hunter dissatisfaction with the number of mature bucks, number of bucks, and number of deer, respectively, to be very extensive or moderate. Even in the northern Lower Peninsula, virtually all of which is affected to a greater or lesser extent by bTB in its deer population, $63 \%$ of responding hunters considered problems with deer herd health to be low or non-existent. Thus, from a bTB management standpoint, MDNR wildlife managers face a fundamental quandary. Michigan deer hunters are concerned about bTB, its potential effects on the health of the deer population, and think it should be a consideration in management of the species. However, they do not consider bTB to be a problem threatening the health of the deer at its current (or perhaps any) level. On the whole, they are unwilling to accept what they consider to be low deer numbers for the sole benefit of cattle producers. Finally, with 673 cattle producers (MDNR, unpublished DCP data) and 56,541 deer hunters (MDNR, 2002) in the five county endemic areas in 2008 , it could be argued that deer hunters understand that they hold the upper hand politically, at least for now.

\section{Current status of $M$. bovis in livestock}

Since the first livestock herd was diagnosed bTB positive in October 1997, there have been 50 herd breakdowns to date. Thirty-five of these were beef herds, 11 were dairy cattle herds, and four were captive WTD facilities. At the time of this writing, there are approximately 13,000 cattle and 520 captive cervid operations statewide (Michigan Departments of Agriculture and Natural Resources, unpublished data). When depopulated, the majority of cattle herds yielded only one $M$. bovis positive animal. Six of the 46 (13\%) cattle herd breakdowns occurred on farms that were infected at least twice. The mean annual rate of herd breakdowns has been 3.5 (range: 2-4) from 2005 to present. All but five (90\%) of the infected herds have been located in the five county endemic areas. This spatiotemporal pattern of infection strongly suggests deer to cattle transmission, and that the risk of cattle herd breakdown is low but relatively constant over a large number of farms. Were that not the case, one would expect specific farms to become infected many more times than they have thus far. While whole herd depopulation has been the preferred disposition for infected livestock facilities, difficulties obtaining sufficient funds for indemnification has become an issue in recent years, particularly for infected captive cervid facilities (the indemnity process provides monetary compensation to farmers whose livestock are condemned and depopulated). Indeed, at the time of this writing, two of the four bTBinfected captive cervid facilities diagnosed to date are still stocked, because money for indemnification of the facility owners is unavailable. Both facilities are located either within DMU 452 or close by, mitigating the risks of allowing them to remain populated, so long as restrictions remain in place on movement of live animals off the infected premises. Even if a bTB-infected deer were to escape from the captive facilities (a not infrequent occurrence; O'Brien et al., 2005), bTB is already present in the surrounding free-ranging WTD population at a prevalence of approximately $1 \%$.

Over the past several years, officials with the Michigan Department of Agriculture (MDA) have focused efforts on moving towards a more risk-based program, with testing and movement controls for livestock comparatively more rigorous for farms located closer to DMU 452. The strategy 
has been motivated not only by both livestock and wildlife surveillance data which overwhelmingly suggests that is where the risk of exposure to infected free-ranging WTD is highest, but also so that increasingly scarce monetary and personnel resources can be expended with the greatest efficiency and impact. Another MDA priority has been encouragement and development of leadership within the livestock industry, in order to promote greater ownership of the Michigan bTB problem by the group that it most affects. In addition, MDA has sought to foster greater public dialogue between livestock owners and hunters/landowners in the five county endemic areas, in the hope of generating greater empathy between the two frequently opposed groups. Research needs related to livestock include identification of cost-effective livestock surveillance programs that do not rely on annual whole herd skin testing in areas of the state where the likelihood of exposure to infected deer is minimal. Farm management practices that minimize the probability of bTB transmission from free-ranging deer to cattle are also a high priority. The MDA has also made a concerted effort to solicit the input of international collaborators in countries with bTB problems in livestock and wildlife. Thus far, the input of New Zealand Animal Health Board officials has been particularly valuable in making practical differences in the Michigan livestock program.

Mitigation of risks of transmission of bTB from freeranging deer to cattle on farms has become a high priority for MDA officials over the past few years. Recognizing that bTB is unlikely to be eradicated from wildlife easily or rapidly (O'Brien et al., 2006), it is essential that cattle producers be proactive in adapting management practices to protect their livestock from exposure until such time as focused wildlife controls can be developed and implemented. The behavior of WTD and cattle makes direct interaction-and so direct transmission of bTB-between the species unlikely. However, indirect transmission via feed has proven to be an efficient route of interspecies transmission in an experimental setting (Palmer et al., 2004a). Consequently, risk mitigation on cattle farms has focused on excluding deer from areas where cattle are fed and feed is stored, typically by fencing (VerCauteren et al., 2006) or guard dogs (VerCauteren et al., 2008b). In addition, producers have been discouraged from allowing livestock to access areas frequented by deer, such as cedar swamps. Adoption of the risk mitigation program has thus far been voluntary for cattle producers, but with incentives (such as less stringent movement testing requirements) to encourage participation. Thus far, prioritization of the more than 650 cattle farms in the five county endemic areas for receiving costshare funds has been the most contentious issue.

\section{Program funding}

To date, MDNR has expended more than US\$23 million on TB-related activities. Over the same period, MDA has spent in excess of US\$62.5 million, and the Michigan Department of Community Health $(\mathrm{MDCH})$, which provides culture and microbiological services, public health consultations, and coordination of bTB communications, more than US\$2.2 million. In 2008, the most recent year for which data are available, the state expended $\sim$ US $\$ 9.6$ million on bTB distributed between MDNR (US\$2.8 million), MDA (US\$6.6 million) and MDCH (US\$257,000). When federal funding is taken into consideration, more than US\$150 million has been expended on the Michigan bTB outbreak thus far, with the vast majority having been spent on surveillance testing of both livestock and freeranging wildlife. Michigan's portion of that funding has primarily come from a dedicated annual appropriation of state general fund monies. Ironically, the constancy of that funding has facilitated support of other programs related to bTB control efforts (such as staffing of deer check stations) which have suffered from budget shortfalls. Currently, Michigan's economy is in serious recession, with the highest seasonally adjusted unemployment rate in the U.S. (15.2\% as of June 2009; U.S. Bureau of Labor Statistics, 2009), and a projected budget deficit of US\$1.7 billion for fiscal year 2010. Funding cuts for bTB surveillance and control programs, potentially dramatic ones, are likely in coming years, barring a rapid and dramatic economic turnaround. This will pose additional challenges for the state agencies involved.

\section{Near term prospects}

Despite these challenges, some current initiatives justify cautious optimism. Promising research to support eventual vaccination of wild WTD continues. Cooperative efforts of the U.S. Department of Agriculture's National Animal Disease Center (NADC) and APHIS-Veterinary Services branch have thus far shown that vaccination of WTD with Bacille Calmette-Guérin (BCG) provides measurable protection against challenge with virulent $M$. bovis, as evidenced by reduced lesion severity scores in vaccinates (Palmer et al., 2007). There is some evidence that the Danish strain of BCG provided more protection than BCG Pasteur (Palmer et al., 2009), and that oral vaccination may provide more protection than vaccination via the parenteral route (Nol et al., 2008). Because venison from hunter-harvested free-ranging WTD is regularly consumed, the safety of vaccinates for human consumption is relevant. The viability and longevity of BCG in tissues of vaccinates has recently been investigated by Palmer et al. (2010). In addition to experimental studies, simulation modeling is underway to assess how vaccination is likely to affect population level transmission of $M$. bovis, simultaneously taking hunter harvest and culling into account (Ramsey et al., 2008). This fully stochastic, spatially explicit model, developed for bTB in brushtailed possums (Trichosurus vulpecula) (Ramsey and Efford, 2010) has been adapted to WTD dynamics and to Michigan habitat potential (Felix et al., 2004, 2007).

In October 2008, in response to the diagnosis of chronic wasting disease of cervids in a captive white-tailed deer, the Michigan Natural Resources Commission (NRC), executive arm of MDNR, expanded the ban on baiting and recreational feeding of WTD from seven counties in the northeast to the entire Lower Peninsula and made the ban permanent. Conservation Officers in the five county endemic areas subsequently reported a substantial improvement in compliance with the baiting ban there. 
Although the step was taken because of concerns about a disease other than bTB, the decreased aggregation of deer that is likely to result from better public compliance with the ban is also likely to decrease intraspecies transmission of bTB.

Of late, there has been recognition on the part of some hunt clubs and private landowners in DMU 452 that deer are so abundant in some areas that they are degrading the habitat, and that some clubs do not apply sufficient harvest pressure to keep the population in check. The argument has been made that competition for existing habitat, and so restrictions on the plane of nutrition for bucks, is a limiting factor for large antlers, a highly sought after characteristic hunters and landowners often seek to maximize. Regardless of whether the argument is based in fact, it has been a motivating factor for some to work towards lower deer densities. This view is by no means unanimous among landowners in the core area, however, and many still complain bitterly about what they consider to be low deer numbers. On the livestock side, some progressive producers have laudably responded to opportunities to meet with hunt clubs, to establish dialogue and better understand the hunter's point of view. Some cattle producers, recognizing their precarious circumstances, have begun work to change long-held prevailing opinions among their peers about farm biosecurity. Such views are often variations on the theme of bTB being “a problem with the DNR's deer", a problem which it is not the livestock producer's responsibility to address. Other producers express what could be interpreted as an attitude of entitlement, that it is the responsibility of government agencies to deal with bTB in a way that requires minimal action, responsibility and commitment on the farmer's part. Cattle producers advocating for change are often progressively managed dairies and purebred beef operations, who because of their substantial investment in genetics, stand the most to lose if their herds become infected and are depopulated. Such producers stand in contrast to many others in the endemic area whose herd management is considerably more casual, and for whom the prospect of $100 \%$ indemnification provides little incentive to take any management actions to protect their herds. Unfortunately for the more progressive producers, their fate is linked to that of other farms in their USDA bTB accreditation zone. The indifference of the least progressive producers can have lasting negative consequences for all.

Yet, formidable challenges remain, and current evidence suggests that eradication of bTB in Michigan, if it can be achieved at all, will take decades, and will require greater public and political resolve than has been demonstrated thus far. There are numerous examples of half-hearted resolve on the part of both hunters and farmers statewide. To some extent, Michiganders who live further away from the endemic area, and so are largely unaffected by agency bTB control efforts there, are more supportive of them. Dorn and Mertig (2005) copiously documented the tendency of hunters who hunt in the endemic area (but reside elsewhere) to view bTB as more serious and justifying stronger control measures than individuals who both hunted and lived in the infected area. However, statewide livestock advocacy groups have repeatedly lobbied for cattle movement restrictions and expanded herd testing requirements associated with USDA bTB accreditation to apply to the smallest possible area, in spite of bTB having been diagnosed in WTD in many areas of the Lower Peninsula. Moreover, they have vocally opposed mandatory farm biosecurity measures and reduced indemnity payments for repeatedly infected herds, even for livestock producers in the core outbreak area. Cattle producers in the endemic area frequently express little hope that they will ever cast off what they consider to be disproportionately burdensome restrictions on their farm operations. Ironically, that resignation gives them little incentive to work towards the broader state and federal goals of bTB eradication. Given the understandable, if regrettable, propensity of humans to act in their own short term self interest, none of this should be surprising.

In many respects, Michigan's current bTB situation poses a classic disease control dilemma. Compared to circumstances in the United Kingdom or South Africa, the prevalence and scope of disease in both free-ranging wildlife and cattle is still low. The goal of eradication could realistically be achieved if sufficient public support existed to underpin political actions to decisively resolve the problem. The public, however, generally does not perceive bTB to be sufficiently problematic to justify strong management actions in either livestock or wildlife. An international research collaborator recently observed that because Michigan has been successful in keeping prevalence low in deer, and therefore in livestock, it has become a victim of its own success, by making the problem too small for people to believe it is important. If prevalence of the disease in the deer were to climb to the point where the population suffered demonstrable ill-effects, or in cattle to the point where the state's agricultural economy was broadly and seriously threatened, more public support likely would follow. At that point however, the magnitude of the problem could be so large that the goal of eradication, if achievable at all, would require vastly greater sacrifices than those at which the people of Michigan currently balk. Fortunately, the potential use of focused strategies such as vaccination provides hope of a way forward which may offer a different, faster road to bTB freedom.

\section{Conflict of interest statement}

The authors have not declared any conflict of interest.

\section{Acknowledgements}

The authors acknowledge the cooperative efforts of the Michigan Bovine Tuberculosis Eradication Project: the Michigan Departments of Agriculture, Community Health, and Natural Resources; the United States Department of Agriculture's Animal and Plant Health Inspection Service Veterinary and Wildlife Services branches; and Michigan State University.

We thank E. Carlson, B. Frawley and B. Rudolph for providing data and references, J. Tilden and M. VanderKlok for information on livestock programs, two anonymous reviewers for insightful comments, and the USDA's National Veterinary Services Laboratory for RFLP TBN12 
strain typing of the 2007 Shiawassee County bTB positive deer. This work was supported by the Federal Aid in Wildlife Restoration Act under Michigan Pittman-Robertson Project W-147-R

\section{References}

Blanchong, J.A., Samuel, M.D., Scribner, K.T., Weckworth, B.V., Langenberg, J.A., Filcek, K.B., 2008. Landscape genetics and the spatial distribution of chronic wasting disease. Biol. Lett. 4, 130-133.

Blanchong, J.A., Scribner, K.T., Winterstein, S.R., 2002. Assignment of individuals to populations: Bayesian methods and multi-locus genotypes. J. Wildl. Manage. 66, 321-329.

Butler, K.L., Fitzgerald, S.D., Berry, D.E., Church, S.V., Reed, W.M., Kaneene, J.B., 2001. Experimental inoculation of European starlings (Sturnus vulgaris) and American crows (Corvus brachyrhynchos) with Mycobacterium bovis. Avian Dis. 45, 709-718.

Clarke, K.A.R., Fitzgerald, S.D., Zwick, L.S., Church, S.V., Kaneene, J.B., Wismer, A.R., Bolin, C.A., Hattey, J.A., Yuzbasiyan-Gurkan, V., 2007. Experimental inoculation of meadow voles (Microtus pennsylvanicus), house mice (Mus musculus), and norway rats (Rattus norvegicus) with Mycobacterium bovis. J. Wildl. Dis. 43, 353-365.

DeLiberto, T.J., 2004. USDA Wildlife Services Update: Environmental sampling: Small mammal study. In: Bovine Tuberculosis in Michigan: Conference 2004, J.B. Henry Center for Executive Development, East Lansing, MI, 9-10 June 2004.

Diegel, K.L., Fitzgerald, S.D., Berry, D.E., Church, S.V., Reed, W.M., Sikarskie, J.G., Kaneene, J.B., 2002. Experimental inoculation of North American opossums (Didelphis virginiana) with Mycobacterium bovis. J. Wildl. Dis. $38,275-281$.

Dorn, M.L., Mertig, A.G., 2005. Bovine tuberculosis in Michigan: stakeholder attitudes and implications for eradication efforts. Wildl. Soc. Bull. 33, 539-552.

Felix, A.B., Campa, H., Millenbah, K.F., Winterstein, S.R., Moritz, W.E., 2004 Development of landscape-scale habitat-potential models for forest wildlife planning and management. Wildl. Soc. Bull. 32, 795-806.

Felix, A.B., Walsh, D.P., Hughey, B.D., Campa, H., Winterstein, S.R., 2007. Applying landscape-scale habitat-potential models to understand deer spatial structure and movement patterns. J. Wildl. Manage. $71,804-810$.

Fitzgerald, S.D., Boland, K.G., Clarke, K.A., Wismer, A., Kaneene, J.B., Berry, D.E., Church, S.V., Hattey, J.A., Bolin, C.A., 2005. Resistance of mallard ducks (Anas platyrynchos) to experimental inoculation with Mycobacterium bovis. Avian Dis. 49, 144-146.

Fitzgerald, S.D., Zwick, L.S., Berry, D.E., Church, S.V., Kaneene, J.B., Reed, W.M., 2003a. Experimental inoculation pigeons (Columba livia) with Mycobacterium bovis. Avian Dis. 47, 470-475.

Fitzgerald, S.D., Zwick, L.S., Diegel, K.L., Berry, D.E., Church, S.V., Sikarskie, J.G., Kaneene, J.B., Reed, W.M., 2003b. Experimental aerosol inoculation of Mycobacterium bovis in North American opossums (Didelphis virginiana). J. Wildl. Dis. 39, 418-423.

Frawley, B.J., 2009. Michigan deer harvest survey report: 2008 seasons. Wildlife Division Report Number 3499. Michigan Department of Natural Resources, Wildlife Division, Lansing, 50 pp.

Frawley, B.J., Rudolph, B.A., 2008. 2006 Deer hunter opinion survey. Wildlife Division Report No. 3482. Michigan Department of Natural Resources, Wildlife Division, Lansing, 29 pp.

Garner, M.S., 2001. Movement patterns and behavior at winter feeding and fall baiting stations in a population of white-tailed deer infected with bovine tuberculosis in the northeastern Lower Peninsula of Michigan. Ph.D. dissertation, Michigan State University, East Lansing, Michigan, $270 \mathrm{pp}$.

Gilsdorf, M.J., Judge, L., Ebel, E.D., 2006. Current challenges to and impacts on the U.S. national bovine tuberculosis eradication program: $M y c o-$ bacterium bovis outbreaks in alternative species and surveillance performance. In: Thoen, C.O., Steele, J.H., Gilsdorf, M.J. (Eds.), Mycobacterium bovis

Hickling, G.J., 2002. Dynamics of bovine tuberculosis in wild white-tailed deer in Michigan. Wildlife Division Report Number 3363. Michigan Department of Natural Resources, Wildlife Division, Lansing, 34 pp.

Hickling, G.J., Schmitt, S.M., O'Brien, D.J., 2003. Spatial and temporal spread of bovine tuberculosis in wild white-tailed deer in Michigan. In: Third International Wildlife Management Congress, Christchurch, New Zealand, December 1-5, p. 61.

Martin, S.W., Meek, A.H., Willeberg, P., 1987. Veterinary Epidemiology: Principles and Methods. Iowa State University Press, Ames, Iowa, pp. 63-64.
Mattson, K.M., Moritz, W.E., 2008. Evaluating differences in harvest data used in the sex-age-kill deer population model. J. Wildl. Manage. 72, 1019-1025.

MDNR, 2002. Deer Management Information System, version 2.1. (Lansing, Michigan).

Nol, P., Palmer, M.V., Waters, W.R., Aldwell, F.E., Buddle, B.M., Triantis, J.M., Linke, L.M., Phillips, G.E., Thacker, T.C., Rhyan, J.C., Dunbar, M.R., Salman, M.D., 2008. Efficacy of oral and parenteral routes of Mycobacterium bovis bacille Calmette-Guérin vaccination against experimental bovine tuberculosis in white-tailed deer (Odocoileus virginianus): a feasibility study. J. Wildl. Dis. 44, 247-259.

O'Brien, D.J., Bernardi, P., Dubay, S., Mayhew, S., Moritz, W., Purol, D., 2005. A risk-based audit of the captive/privately owned cervid industry in Michigan. Michigan Department of Natural Resources Report Series, Issue Report Number 1. Michigan Department of Natural Resources, Lansing, $168 \mathrm{pp}$.

O'Brien, D.J., Fitzgerald, S.D., Lyon, T.J., Butler, K.L., Fierke, J.S., Clarke, K.R., Schmitt, S.M., Cooley, T.M., Berry, D.E., 2001. Tuberculous lesions in free-ranging white-tailed deer in Michigan. J. Wildl. Dis. 37, 608-613.

O'Brien, D.J., Schmitt, S.M., Berry, D.E., Fitzgerald, S.D., Lyon, T.J., Vanneste, J.R., Cooley, T.M., Hogle, S.A., Fierke, J.S., 2008. Estimating the true prevalence of Mycobacterium bovis in free-ranging elk in Michigan. J. Wildl. Dis. 44, 802-810.

O’Brien, D.J., Schmitt, S.M., Berry, D.E., Fitzgerald, S.D., Vanneste, J.R., Lyon, T.J., Magsig, D., Fierke, J.S., Cooley, T.M., Zwick, L.S., Thomsen, B.V., 2004 Estimating the true prevalence of Mycobacterium bovis in hunter-harvested white-tailed deer in Michigan. J. Wildl. Dis. 40, 42-52.

O'Brien, D.J., Schmitt, S.M., Fierke, J.S., Hogle, S.A., Winterstein, S.R., Cooley, T.M., Moritz, W.E., Diegel, K.L., Fitzgerald, S.D., Berry, D.E., Kaneene, J.B., 2002. Epidemiology of Mycobacterium bovis in freeranging white-tailed deer, Michigan, USA 1995-2000. Prev. Vet. Med. 54, 47-63.

O'Brien, D.J., Schmitt, S.M., Fitzgerald, S.D., Berry, D.E., Hickling, G.J., 2006. Managing the wildlife reservoir of Mycobacterium bovis: the Michigan, USA, experience. Vet. Microbiol. 112, 313-323.

Palmer, M.V., Thacker, T.C., Waters, W.R., 2007. Vaccination of whitetailed deer (Odocoileus virginianus) with Mycobacterium bovis bacillus Calmette Guérin. Vaccine 25, 6589-6597.

Palmer, M.V., Thacker, T.C., Waters, W.R., 2009. Vaccination with Mycobacterium bovis BCG strains Danish and Pasteur in white-tailed deer (Odocoileus virginianus) experimentally challenged with Mycobacterium bovis. Zoonoses Public Health 56, 243-251.

Palmer, M.V., Waters, W.R., Whipple, D.L., 2002a. Lesion development in white-tailed deer (Odocoileus virginianus) experimentally infected with Mycobacterium bovis. Vet. Pathol. 39, 334-340.

Palmer, M.V., Waters, W.R., Whipple, D.L., 2002b. Susceptibility of raccoons (Procyon lotor) to infection with Mycobacterium bovis. J. Wildl. Dis. 38, 266-274.

Palmer, M.V., Waters, W.R., Whipple, D.L., 2004a. Investigation of the transmission of Mycobacterium bovis from deer to cattle through indirect contact. Am. J. Vet. Res. 65, 1483-1489.

Palmer, M.V., Waters, W.R., Whipple, D.L., 2004b. Shared feed as a means of deer-to-deer transmission of Mycobacterium bovis. J. Wildl. Dis. 40 87-91.

Palmer, M.V., Whipple, D.L., 2006. Survival of Mycobacterium bovis on feedstuffs commonly used as supplemental feed for white-tailed deer (Odocoileus virginianus). J. Wildl. Dis. 42, 853-858.

Palmer, M.V., Whipple, D.L., Olsen, S.C., 1999. Development of a model of natural infection with Mycobacterium bovis in white-tailed deer. J. Wildl. Dis. 35, 450-457.

Palmer, M.V., Whipple, D.L., Waters, W.R., 2001. Experimental deer-todeer transmission of Mycobacterium bovis. Am. J. Vet. Res. 62, 692696.

Palmer, M.V., Thacker, T.C., Waters, W.R., Robbe-Austerman, S., LebepeMazur, S.M., Harris, N.B., 2010. Persistence of Mycobacterium bovis Bacillus Calmette-Guérin (BCG) in white-tailed deer (Odocoileus virginianus) after oral or parenteral vaccination. Zoonoses Public Health 57, e206-e212.

Ramsey, D.S.L., Efford, M.G., 2010. Management of bovine tuberculosis in brushtail possums in New Zealand: predictions from a spatially explicit, individual-based model. J. Appl. Ecol. 47, 911-919.

Ramsey, D.S.L., O’Brien, D.J., Schmitt, S.M., Hickling, G.J., 2008. Towards a spatially explicit model of bovine TB in white-tailed deer. In: 2008 Michigan Bovine TB Scientific Meeting, J.B. Henry Center for Executive Development, Michigan State University, East Lansing, Michigan, 2324 July, 2008.

Rogan, W.J., Gladen, B., 1978. Estimating prevalence from the results of a screening test. Am. J. Epidemiol. 107, 71-76.

Rudolph, B.A., Riley, S.J., Hickling, G.J., Frawley, B.J., Garner, M.S., Winterstein, S.R., 2006. Regulating hunter baiting for white-tailed deer in 
Michigan: biological and social considerations. Wildl. Soc. Bull. 34, 314-321.

Schmitt, S.M.. Fitzgerald, S.D., Cooley, T.M., Bruning-Fann, C.S., Sullivan, L. Berry, D., Carlson, T., Minnis, R.B., Payeur, J.B., Sikarskie, J., 1997. Bovine tuberculosis in free-ranging white-tailed deer from Michigan. J. Wildl. Dis. 33, 749-758.

Schmitt, S.M., O'Brien, D.J., Bruning-Fann, C.S., Fitzgerald, S.D., 2002. Bovine tuberculosis in Michigan wildlife and livestock. Ann. N. Y. Acad. Sci. 969, 262-268.

Scribner, K.T., 2008. Memorandum re: analyses of suspect TB+samples from Shiawassee County, Michigan. Department of Fisheries and Wildlife, Michigan State University, 4 pp.

Sitar, K.L., 1996. Seasonal movements, habitat use patterns, and population dynamics of white-tailed deer (Odocoileus virginianus) in an agricultural region of northern Lower Michigan. M.S. thesis, Michigan State University, East Lansing, MI, $130 \mathrm{pp}$

U.S. Department of the Interior, 2008. 2006 National Survey of Fishing, Hunting, and Wildlife-Associated Recreation-Michigan. United States Department of Interior, Fish and Wildlife Service, and United
States Department of Commerce, Census Bureau, Washington, D.C., $91 \mathrm{pp}$.

U.S. Bureau of Labor Statistics, 2009. Unemployment rates for states, monthly rankings, seasonally adjusted, June 2009. United States Department of Labor, Bureau of Labor Statistics. <http:// www.bls.gov/web/laumstrk.htm>, (accessed 03.08.09.).

VerCauteren, K.C., Atwood, T.C., DeLiberto, T.J., Smith, H.J., Stevenson, J.S., Thomsen, B.V., Gidlewski, T., Payeur, J., 2008a. Sentinel-based surveillance of coyotes to detect bovine tuberculosis, Michigan. Emerg. Infect. Dis. 14, 1862-1869.

VerCauteren, K.C., Lavelle, M.J., Hygnstrom, S., 2006. Fences and deerdamage management: a review of designs and efficacy. Wildl. Soc. Bull. 34, 191-200.

VerCauteren, K.C., Lavelle, M.J., Phillips, G.E., 2008b. Livestock protection dogs for deterring deer from cattle and feed. J. Wildl. Manage. 72, 1443-1448.

Wilkins, M.J., Bartlett, P.C., Berry, D.E., Perry, R.L., Fitzgerald, S.D., Bernardo, T.M., Thoen, C.O., Kaneene, J.B., 2008. Absence of Mycobacterium bovis infection in dogs and cats residing on infected cattle farms: Michigan, 2002. Epidemiol. Infect. 136, 1617-1623. 